УДК 615.36:547.454 012

\title{
ИЗУЧЕНИЕ КОМПЛЕКСООБРАЗОВАНИЯ АРАБИНОГАЛАКТАНА ЛИСТВЕННИЦЫ СИБИРСКОЙ И ЕГО ОКИСЛЕННЫХ ФРАКЦИЙ с йодом
}

\author{
() Р.Х. Мударисова ${ }^{1 *}$, Р.М. Исламова ${ }^{1,2}$ \\ ${ }^{1}$ Институт органической химии Уфримского научного центра РАН, \\ пр. Октября, 71, Уфра, 450054 (Россия), e-mail: mudarisova@anrb.ru \\ ${ }^{2}$ Санкт-Петербургский государственный университет, Университетский пр., \\ 26, Петергоф, Санкт-Петербург, 198504 (Россия), e-mail: rmislamova@mail.ru
}

\begin{abstract}
Спектрофотометрическими методами исследована термодинамика комплексообразования систем йод - арабиногалактан, йод - полимерная форма окисленного арабиногалактана и йод - олигомерная форма окисленного арабиногалактана в водных и водно-спиртовых растворах при различных температурах. Установлены состав и константы устойчивости образующихся комплексов, оптимальные условия реакции. Выявлена связь между донорной способностью полисахаридных матриц и устойчивостью продуктов реакции. Рассчитаны изменения энтальпии и энтропии реакции. Обнаружено, что в поли- и олигосахаридах активными центрами, непосредственно вступающими в реакции взаимодействия с йодом, являются как гидроксильные группы, так и эфирная С-О связь пиранозных и фуранозных колец поли- и олигосахаридов.

Ключевые слова: арабиногалактан и его окисленные формы, йод, комплексообразование, спектроскопия, константы стабильности, энтальпия, энтропия
\end{abstract}

\section{Введение}

Известно, что комплексы биополимеров с лекарственными веществами часто оказываются более эффективными, чем индивидуальные фармаконы. К полимерам такого плана относится и полисахарид арабиногалактан (АГ), получаемый водной экстракцией из древесины лиственницы сибирской. АГ обладает уникальным комплексом свойств: высокая водорастворимость, аномально низкая вязкость концентрированных водных растворов, оптическая активность, иммуномодулирующая, противоопухолевая и антиоксидантная активности и способность к биодеградации [1-7]. В этой связи АГ представляет собой интерес как полимерная матрица - носитель лекарственных веществ для придания им повышенной биодоступности и пролонгированности действия. [8].

Исследования последних лет показали перспективность применения олигомеров природных полисахаридов, в частности арабиногалактанов, как основных компонентов лекарственных средств [9]. Было установлено, что окисленные формы АГ, представляющие собой продукты окисления лиственничного АГ, обладают более высокой физиологической активностью, чем исходный полимер [10]. Поэтому получение межмолекулярных комплексов на основе АГ и его окисленных форм с лекарственными соединениями вызывает несомненный интерес. Целью настоящей работы явилось исследование взаимодействия АГ и его

Мударисова Роза Ханифовна - кандидат химических наук, старший научный сотрудник лаборатории стереорегулярных полимеров,

e-mail: mudarisova@anrb.ru Исламова Регина Маратовна - доктор химических наук, профессор кафедры металлоорганических соединений, e-mail: rmislamova@mail.ru окисленных форм с йодом и получение на их основе новых соединений, обладающих физиологической активностью. Взаимодействие лекарственного вещества с поли- и олигосахаридами может обеспечить пролонгированность действия и существенно снизить токсичность исходного препарата за счет сокращения дозы лекарственного вещества [9].

\footnotetext{
* Автор, с которым следует вести переписку.
} 


\section{Экспериментальная часть}

В эксперименте использовали арабиногалактан с молекулярной массой 40000, выделенный водной экстракцией из древесины лиственницы сибирской [11]. Для определения молекулярной массы АГ и окисленной полимерной формы (АГ пол $)$ был использован метод сочетания скоростной седиментации и вискозиметрии. Значения молекулярной массы рассчитывались по формуле:

$$
\mathrm{M}_{\mathrm{S}[\eta]}=\left[\mathrm{S}_{0} \eta_{0}[\eta]^{1 / 3} \mathrm{~N}_{\mathrm{A}} / \phi^{1 / 3} \mathrm{p}^{-1}\left(1-\mathrm{V} \rho_{0}\right)\right]^{3 / 2}
$$

где $\mathrm{S}_{0}$ - константа седиментации; $\eta_{0}$ - динамическая вязкость растворителя; [ๆ] - характеристическая вязкость соединения; $\mathrm{N}_{\mathrm{A}}$ - число Авогадро; $\phi^{1 / 3} \mathrm{p}^{-1}=2,71 \cdot 10^{6}$ - гидродинамический инвариант; 1 - V $\rho_{0}-$ фактор плавучести (Архимедов множитель), определялся пикнометрически.

Молекулярная масса АГ пол составила 22000. Определение молекулярной массы окисленной олигомерной формы $\left(\mathrm{A} \Gamma_{\text {ол }}\right)$ проводили методом седиментационного равновесия [12]. Молекулярная масса $\left(\mathrm{A} \Gamma_{\text {ол }}\right)$ составила 4000.

Выделение и очистку АГ от растворимых в воде фенольных соединений, в том числе дигидрокверцетина, проводили на полиамидном сорбенте. При этом получали водный раствор полисахарида, содержащий флавоноиды в следовых количествах (0,01-0,05\% вес). Окислительную функционализацию АГ проводили путем окисления его водных растворов пероксидом водорода в присутствии молекулярного кислорода в стеклянном реакторе барботажного типа. Объем реакционной смеси составлял 10 мл, по окончании реакции полимерную форму окисленного АГ отделяли от олигомерной осаждением ацетоном. Олигомерную форму выделяли из надосадочной жидкости путем отгона ацетона и воды с последующей сушкой продукта в вакууме. Анализ функциональных групп АГ, полимерной и олигомерной форм приведен ранее в работах $[13,14]$. В эксперименте использовали йод металлический, марки ч., дважды возогнанный. ИКспектры образцов записывали на спектрофотометре Specord M-80 в вазелиновом масле. УФ-спектры водных и водно-спиртовых растворов соединений снимали в кварцевых кюветах толщиной 1 см относительно воды на спектрофотометре Specord M-40. Суммарная концентрация поли-, олигосахаридов и йода в изомолярной серии была постоянной, $1 \times 10^{-4}$ моль/л. Молярные отношения [АГ]/[ $\left.\mathrm{I}_{2}\right]$ варьировали от 50/1 до 1/20. В сериях растворов с постоянной концентрацией йода, равной $1 \times 10^{-4}$ моль/л, концентрацию АГ и его окисленных форм изменяли от $0,25 \times 10^{-4}$ и до $1 \times 10^{-2}$ моль/л.

\section{Обсуждение результатов}

Электронные спектры водных растворов АГ, йода и их смеси приведены на рисунке 1. При смешении АГ и/или его окисленных форм с йодом в УФ области спектра наблюдается резкое повышение интенсивности полос поглощения ионов $\mathrm{J}_{3}{ }^{-}$, а максимумы поглощения сдвигаются в сторону меньших длин волн на 3-5 нм, в то же время в видимой области спектра происходит понижение интенсивности полосы поглощения свободного йода и ее гипсохромный сдвиг на 5-7 нм. Спектральные изменения свидетельствуют о влиянии, оказываемом поли- и олигосахаридами на электронную систему йода, и образовании ком-

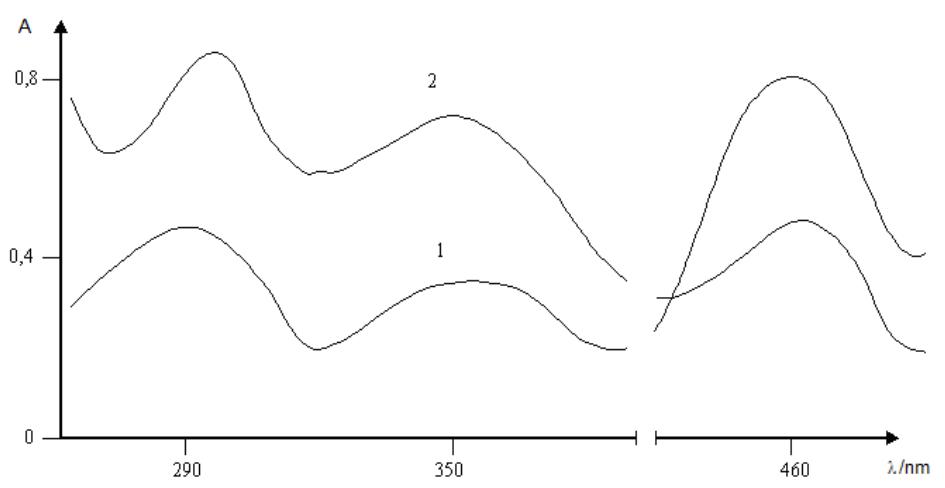

Рис. 1. УФ-спектр йода (1), $\mathrm{I}_{2}+\mathrm{AГ} \mathrm{(2),} \mathrm{растворитель} \mathrm{H}_{2} \mathrm{O}$; $\mathrm{C}\left(\mathrm{I}_{2}\right)=1,0 \times 10^{-4}$ моль $/$ л, $\mathrm{C}(\mathrm{AG})=1,0 \times 10^{-4}$ моль $/$ л, $1=1,0 \mathrm{~cm}$. $\mathrm{T}=20^{\circ} \mathrm{C}$ плексных соединений. В процессе взаимодействия АГ и/или его окисленных форм с йодом происходит быстрое образование трииодид-ионов в течение первых минут реакции, тогда как интенсивность полосы поглощения свободного йода постепенно падает.

По методу изомолярных серий [15] было установлено, что соотношение стехиометрических коэффициентов для всех исследуемых комплексов составляет 1:1 (рис. 2). Для выяснения механизма взаимодействия АГ и его окисленных форм с йодом важное значение имеют термодинамиче- 
ские характеристики реакции. При нескольких температурах $(0,20$, $40{ }^{\circ} \mathrm{C}$ ) изучалось изменение оптической плотности растворов с постоянной общей концентрацией йода при меняющейся концентрации АГ и/или его окисленных форм и наоборот. Константы комплексообразования рассчитывали для трех температур по методу мольных отношений [15]. Из таблицы 1 видно, что устойчивость комплексов с повышением температуры падает, что характерно для соединений полисахаридов с йодом [16]. Константы устойчивости комплексов увеличиваются в порядке $\mathrm{A} Г>\mathrm{A} \Gamma_{\text {пол }}>\mathrm{A} \Gamma_{\text {ол }}$ Константы взаимодействия исходного полисахарида с йодом гораздо выше, чем с его окисленными фракциями. АГ пол и $А \Gamma_{\text {ол }}$, как и следовало ожидать, являются более сильными электроно-акцепторами, чем АГ, так как содержат большее количество карбоксильных групп (12 и $76 \%$ соответственно).

Тепловые эффекты реакции образования комплекса (табл. 2) были вычислены по уравнению ВантГоффа в интегральной форме:

$$
\Delta H^{0}=4,575 \cdot\left(\lg \beta_{\kappa}^{\prime \prime} / \beta_{\kappa}^{\prime}\right) /\left(1 / T_{1}-1 / T_{2}\right)[17] .
$$

Из анализа энтальпийных характеристик следует, что на значения констант устойчивости большое влияние оказывает как длина цепи поли- и олигосахаридов, их строение, так и содержание функциональных групп. Известно [18], что с увеличением констант устойчивости комплексов значения $\Delta \mathrm{H}^{0}$ и $\Delta \mathrm{S}^{0}$, как правило, становятся более отрицательными, т.е. донор и акцептор физически прочнее удерживаются по мере упрочнения связи между ними. Так, для исходного АГ значения энтальпии и энтропии меньше, чем для его окисленных фракций. Это может быть связано с большей донорной способностью исходного АГ по сравнению с АГ пол и АГ ол. Более высокое значение энтальпии для реакции йода с АГ и его окисленными фракциями по сравнению с такими полимерами, как поливиниловый спирт, крахмал, амилоза, вероятно, можно объяснить большими энергетическими затратами при образовании комплексов. Это может быть в первую очередь связано с разветвленной структурой АГ и его окисленных форм, которая создает стерические затруднения при протекании реакции с йодом.

Изменение энтропии вычислено по формуле:

$$
\Delta S^{0}=\left(\Delta H^{0}-\Delta G^{0}\right) / T[17]
$$

где $\Delta \mathrm{G}^{0}=-\mathrm{RT} \ln \beta_{\mathrm{k}}$ (изменение свободной энергии); $\Delta \mathrm{H}^{0}-$ тепловой эффект реакции; $\mathrm{T}-$ средняя температура.

Таблица 1. Константы устойчивости комплексов в водной среде

\begin{tabular}{c|c|c|c}
\hline \multirow{2}{*}{$\mathrm{T}, \mathrm{K}$} & \multicolumn{3}{|c}{$\left(\beta_{\mathrm{K}} \times 10^{-3}\right), \mathrm{L} / \mathrm{mol}$} \\
\cline { 2 - 4 } & $\mathrm{AG}+\mathrm{I}_{2}$ & $\mathrm{AG}_{\mathrm{pol}}+\mathrm{I}_{2}$ & $\mathrm{AG}_{\mathrm{ol}}+\mathrm{I}_{2}$ \\
\hline 273 & 3,0 & 2,2 & 0,9 \\
293 & 2,6 & 1,4 & 0,5 \\
313 & 1,5 & 0,7 & 3,1 \\
$293^{*}$ & 4,0 & 3,2 & 0,5 \\
\hline
\end{tabular}

*растворитель вода - этиловый спирт $(1: 1)$

Таблица 2. Термодинамические характеристики комплексов

\begin{tabular}{c|c|c}
\hline Комплекс & $-\Delta \mathrm{H}^{0}, \mathrm{~kJ} / \mathrm{mol}$ & $-\Delta \mathrm{S}^{0}, \mathrm{~J} / \mathrm{mol} \times \mathrm{K}$ \\
\hline $\mathrm{AG}+\mathrm{I}_{2}$ & 32 & 55 \\
$\mathrm{AG}_{\mathrm{pol}}+\mathrm{I}_{2}$ & 24 & 24 \\
$\mathrm{AG}_{\mathrm{ol}}+\mathrm{I}_{2}$ & 24 & 27 \\
\hline
\end{tabular}


Меньшее изменение энтропии (табл. 1) в данном случае по сравнению с другими известными системами [18], очевидно, связано с тем, что в процессе взаимодействия, например, амилозы с йодом наблюдается ориентация биомолекул около молекул йода в виде спирали, тогда как в случае реакции АГ и его окисленных форм с йодом, возможно, не происходит существенных структурных перестроек поли- и/или олигосахаридов и наблюдается меньшая упорядоченность при образовании комплексов. Согласно литературным данным [18], изменение энтропии при комплексообразовании амилозы с йодом включает вклады: 1) конформационных изменений молекулы амилозы при вхождении в нее полииодидной цепи $(\Delta S<0), 2)$ перехода трииодид-ионов из объема раствора в мономерную линейную структуру $(\Delta \mathrm{S}<0), 3)$ дегидратация молекул йода $(\Delta \mathrm{S}<0)$. Можно предположить, что при комплексообразовании АГ изменение энтропии включает лишь два и три взаимодействия, тогда как конформационные изменения молекулы АГ очень незначительны.

Из литературы [18] известно, что константы устойчивости трииодидных комплексов весьма чувствительны к природе растворителя. При переходе от воды к неводным растворителям показатель константы в зависимости от типа растворителя может изменяться на величину до пяти порядков. Различие в устойчивости трииодидных комплексов в растворителях различной природы можно связать с влиянием среды на сольватацию иодид-иона. В связи с этим были проведены эксперименты по изучению комплексообразования АГ и/или его окисленных форм с йодом при $21^{\circ} \mathrm{C}$ в смеси: вода + этиловый спирт $(1: 1)$. Расчет константы устойчивости показал, что она возрастает во всех случаях примерно в 2-3,5 раза больше, чем в воде (табл. 1). По-видимому, различие в устойчивости трииодидных комплексов в воде и в ее смеси с этиловым спиртом связано с тем, что в водной среде возможность взаимодействия иодид-иона с молекулой йода ограничена изза высокой степени сольватации иодид-иона, а этиловый спирт в меньшей степени препятствует образованию связи йод - иодид, поэтому в полярном растворителе образуются более устойчивые комплексы.

Для выяснения механизма процесса взаимодействия АГ и его окисленных форм с йодом и исключения влияния растворителя на реакцию было проведено допирование тонких пленок поли- и олигосахаридов парами йода. На рисунке 3 на примере АГ показаны изменения, происходящие в электронных спектрах полисахарида на начальных стадиях допирования при $\mathrm{T}=40^{\circ} \mathrm{C}$. Выдержка АГ в парах йода в течение 5 мин вызывает появление полосы поглощения с $\lambda_{\max }=290$ нм, которую можно отнести к поглощению ионов $I_{3}^{-}$. Следовательно, в процессе комплексообразования йод вступает во взаимодействие с АГ и в свободном виде в полисахариде не существует. Увеличение времени допирования до 15 мин приводит к усилению полосы поглощения $I_{3}^{-}$. При дальнейшем увеличении времени допирования до 45 мин наблюдается дальнейшее повышение интенсивности полосы поглощения 290 нм и появление новой полосы поглощения в области 370-400 нм, которую можно отнести к поглощению $I_{5}^{-}$[19]. Из приведенных экспериментальных данных видно, что на начальной стадии допирования происходит образование комплекса полисахарида с трииодидом, дальнейшее допирование приводит к формированию полииодидов, которые обладают большей стабильностью в полимерах [19].

Синтез комплексов АГ его окисленных фракций с йодом проводили при комнатной температуре в течение 2 ч. Содержание йода в продуктах реакции составило от 43 до 59\%. Выделенные соединения были проанализированы спектрофотометрическими методами исследования. В электронном спектре комплексов наблюдаются полосы поглощения 285 нм и 344 нм, соответствующие колебаниям трииодидных

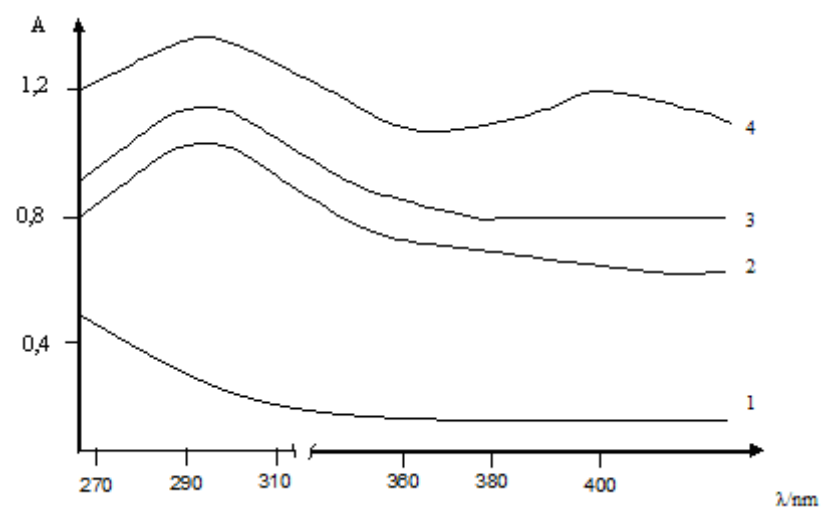

Рис. 3. УФ-спектры тонкой пленки АГ на кварцевой подложке, в зависимости от времени допирования; $\mathrm{T}=40{ }^{\circ} \mathrm{C} ; 1-0 ; 2-5$ мин; $3-15$ мин; $4-45$ мин ионов. Согласно данным ИК-спектроскопии в йодсодержащих комплексах наблюдается увеличение интенсивности, а также смещение полос поглощения валентных колебаний гидроксильных групп на 20-30 см${ }^{-1}$ (3350-3250 $\mathrm{cm}^{-1}$ ) и полос поглощения в области 1200-1000 $\mathrm{cm}^{-1}$, соответствующих валентным колебаниям эфирной С-О связи пиранозного и фуранозного циклов, на $10-15 \mathrm{~cm}^{-1}$ в низкочастотную область. Из полученных спектральных данных можно сделать вывод, что главными активными центрами в поли- и олигосахаридах, участвующими во взаимодействии с йодом, могут быть как гидроксильные группы, так и эфирная С-О связь. 


\section{Выводы}

1. Установлено формирование стехиометрических комплексов АГ (окисленная форма АГ) - йод. Показано, что понижение температуры реакции и повышение полярности растворителя увеличивают устойчивость продуктов реакции.

2. Термодинамические характеристики процесса комплексообразования биополимер - йод указывают, на то, что при взаимодействии компонентов системы не происходит существенных структурных перестроек поли- и олигосахаридов.

3. Показано, что главными активными центрами в АГ и в его окисленных формах, участвующими во взаимодействии с йодом, могут быть как гидроксильные группы, так и эфирная связь пиранозного и фуранозного циклов.

\section{Список литературы}

1. Антонова Г.Д., Тюкавкина Н.А. Некоторые вопросы экстракции водорастворимых полисахаридов древесины сибирской лиственницы // Химия древесины. 1983. №2. С. 89-96.

2. Арифходжаев А.О. Галактаны и галактансодержащие полисахариды высших растений // Химия природных соединений. 2000. Т. 36. № 3. С. 185-197.

3. Yamada H., Kiyhara H., Cyong J.C., Otsuka Y. Structural characterization of an anti-complementary arabinogalactan from the roots of Angelica acutiloba Kitagawa // Carbohydrate. Res. 1987. Vol. 159. N3. Pp. 275-291.

4. Медведева Е.Н., Бабкин В.А., Остроухова Л.А. Арабиногалактан лиственницы - свойства и перспективы использования // Химия растительного сырья. 2003. №1. С. 27-37.

5. Оводов Ю.С. Полисахариды цветковых растений: структура и физиологическая активность // Биоорганическая химия. 1998. Т. 24. №7. С. 483-501.

6. Kiyohara H., Yamada H. Structure of an anti-complementary arabinogalactan from the roots of Angelica acutiloba Kitagawa // Carbohydrate Research. 1989. Vol. 193. N10. Pp. 173-192.

7. Gonda R., Tomoda M., Ohara N., Takada K. Arabinogalactan core structure and immunological activities of ukonan C, an acidic polysaccharide from the rhizome of Curcuma longa // Biol. Pharm. Bull. 1993. Vol. 16. №3. Pp. 235-238.

8. Мударисова Р.Х., Бадыкова Л.А., Азаматова Г.А., Исламова Р.М., Азнабаев М.Т. Полимерные глазные пленки на основе поливинилового спирта и арабиногалактана с левофлоксацином // Журнал прикладной химии. 2013. T. 86. №4. C. 650-654.

9. Мударисова Р.Х., Бадыкова Л.А. Взаимодействие арабиногалактана лиственницы сибирской с аминосодержащими соединениями // ВМС. Серия А. 2012. Т. 54. №2. С. 237-243.

10. Мударисова Р.Х., Широкова Е.Н., Бадыкова Л.А., Толстикова Т.Г., Сорокина И.В., Долгих М.П., Монаков Ю.Б. Синтез и фармакологическая активность окисленных фракций арабиногалактана лиственницы сибирской (Larix sibirica L.) // Химико-фармацевтический журнал. 2005. Т. 39. №8. С. 23-26.

11. Антонова Г.Ф., Усов А.И. Структура арабиногалактана древесины лиственницы сибирской (Larix sibirica L.). // Биоорганическая химия. 1984. Т.10, № 12. С. 1664-1669.

12. Рафиков С.Р., Будтов В.Т., Монаков Ю.Б. Введение в физико-химию растворов полимеров. М., 1978. 328 с.

13. Борисов И.М., Широкова Е.Н., Мударисова Р.Х., Муслухов Р.Р., Зимин Ю.С., Медведева С.А., Толстиков Г.А., Монаков Ю.Б. Кинетика окисления арабиногалактана лиственницы (Larix sibirica L.) в водной среде в присугствии пероксида водорода // Известия АН. Сер. хим. 2004. Т. 53. №2. С. 305-311.

14. Monakov Yu.B., Borisov I.M., Zimin Yu.S., Mudarisova R.Kh., Tolstikova T.G., Shirokova E.N., Medvedeva S.A., Zaikov G.E. Peroxide oxidation of Arabinogalactan of Siberian Larch. Kinetics and products // Oxidation Communications. 2005. Vol. 28. №2. Pp. 472-479.

15. Булатов М.И., Калинкин И.П., Практическое руководство по фотометрическим методам анализа. Ленинград, 1986. $432 \mathrm{c}$

16. Владимиров А.В., Волкова Т.В., Агафонов А.В. Температурная зависимость констант устойчивости комплекса йод-иодид-амилоза // Журнал физической химии. 2003. Т. 77. №4. С. 690-693.

17. Яцимирский К.Б., Морозова Р.П. Некоторые термодинамические характеристики реакции образования йодкрахмала // Известия вузов. 1963. №6. С. 925-929.

18. Агафонов А.В. Йод как молекулярный зонд и биологически активный элемент // Биологически активные вещества в растворах. Структура, термодинамика, реакционная способность. М., 2001. С. 9-46.

19. Калниньш К.К., Любимова Г.В. О природе низкочастотного поглощения в электронных спектрах комплексов йода // Журнал физической химии. 1983. Т. 57. №12. С. 2995-2998. 


\section{WITH IODINE \\ Mudarisova R.Kh. ${ }^{1 *}$, Islamova R.M. ${ }^{1,2}$ COMPLEXATION OF ARABINOGALACTAN AND ITS OXIDIZED FORMS}

${ }^{1}$ Institute of Organic Chemistry of Ufa Scientific Centre of the Russian Academy of Sciences, pr. October, 71, Ufa,

450054 (Russia), e-mail: mudarisova@anrb.ru

${ }^{2}$ Saint Petersburg State University, Universitetsky Pr., 26, Stary Petergof, 198504 (Russia),

e-mail: rmislamova@mail.ru

Thermodynamics of a complex formation of iodine and arabinogalactan, iodine and polymeric form oxidized arabinogalactan, iodine and oligomeric form of oxidized arabinogalactan in water and aqueous-alcoholic solutions at various temperatures by spectrophotometry methods was investigated. Structure and constants of stability of formed complexes, optimum conditions of reaction were established. Communication between donor ability of polysaccharide matrixes and stability of reaction products was revealed. Changes of enthalpy and entropy of reaction were calculated. There are no essential restructurings of compounds at iodine complex formation with arabinogalactan or its oxidized forms. The active centers in poly-and oligosaccharides which are directly reacting with iodine are both hydroxyl groups, and C-O ether bond of pyranose and furanose rings of poly- and oligosaccharides.

Keywords: arabinogalactan and its oxidized form, iodine complexing, spectroscopy, stability constants, enthalpy, entropy.

\section{References}

1. Antonova G.D., Tjukavkina N.A. Himija drevesiny, 1983, no. 2, pp. 89-96. (in Russ.).

2. Arifhodzhaev A.O. Himija prirodnyh soedinenij, 2000, vol. 36, no. 3, pp. 185-197. (in Russ.).

3. Yamada H., Kiyhara H., Cyong J.C., Otsuka Y. Carbohydrate. Res. 1987, vol. 159, no. 3, pp. $275-291$.

4. Medvedeva E.N., Babkin V.A., Ostrouhova L.A. Himija rastitel'nogo syr'ja, 2003, no. 1, pp. 27-37. (in Russ.).

5. Ovodov Ju.S. Bioorganicheskaja himija, 1998, vol. 24, no. 7, pp. 483-501. (in Russ.).

6. Kiyohara H., Yamada H. Carbohydrate Research. 1989, vol. 193, no. 10, pp. 173-192.

7. Gonda R., Tomoda M., Ohara N., Takada K. Biol. Pharm. Bull. 1993, vol. 16, no. 3, pp. 235-238.

8. Mudarisova R.H., Badykova L.A., Azamatova G.A., Islamova R.M., Aznabaev M.T. Zhurnal prikladnoj himii, 2013, vol. 86, no. 4, pp. 650-654. (in Russ.).

9. Mudarisova R.H., Badykova L.A. VMS. Serija A. 2012, vol. 54, no. 2, pp. 237-243. (in Russ.).

10. Mudarisova R.H., Shirokova E.N., Badykova L.A., Tolstikova T.G., Sorokina I.V., Dolgih M.P., Monakov Ju.B. Himiko-farmacevticheskij zhurnal, 2005, vol. 39, no. 8, pp. 23-26. (in Russ.).

11. Antonova G.F., Usov A.I. Bioorganicheskaja himija, 1984, vol.10, no. 12, pp. 1664-1669. (in Russ.).

12. Rafikov S.R., Budtov V.T., Monakov Ju.B. Vvedenie v fiziko-himiju rastvorov polimerov. [Introduction to physicochemistry of polymer solutions]. Moscow, 1978, 328 p. (in Russ.).

13. Borisov I.M., Shirokova E.N., Mudarisova R.H., Musluhov R.R., Zimin Ju.S., Medvedeva S.A., Tolstikov G.A., Monakov Ju.B. Izvestija AN. Ser. him. 2004, vol. 53, no. 2, pp. 305-311. (in Russ.).

14. Monakov Yu.B., Borisov I.M., Zimin Yu.S., Mudarisova R.Kh., Tolstikova T.G., Shirokova E.N., Medvedeva S.A., Zaikov G.E. Oxidation Communications, 2005, vol. 28, no. 2, pp. 472-479.

15. Bulatov M.I., Kalinkin I.P. Prakticheskoe rukovodstvo po fotometricheskim metodam analiza. [A Practical Guide to the photometric analysis methods]. Leningrad, 1986. 432 p. (in Russ.).

16. Vladimirov A.V., Volkova T.V., Agafonov A.V. Zhurnal fizicheskoj himii, 2003, vol. 77, no. 4, pp. 690-693. (in Russ.).

17. Jacimirskij K.B., Morozova R.P. Izvestija vuzov. 1963, no. 6, pp. 925-929. (in Russ.).

18. Agafonov A.V. Biologicheski aktivnye veshhestva v rastvorah. Struktura, termodinamika, reakcionnaja sposobnost'. [Biologically active substances in solution. Structure, thermodynamics, reactivity]. Moscow, 2001, pp. 9-46. (in Russ.).

19. Kalnin'sh K.K., Ljubimova G.V. Zhurnal fizicheskoj himii, 1983, vol. 57, no. 12, pp. 2995-2998. (in Russ.).

Received February 4, 2014

Revised September 30, 2014

\footnotetext{
* Corresponding author.
} 